\title{
Propriedade antimicrobiana e perfil de toxicidade de méis de abelhas sem ferrão do gênero Melipona Illiger, 1806: Uma revisão integrativa
}

Antimicrobial property and toxicity profile of bee honey bees of the gender Melipona Illiger, 1806: An integrative review

Propiedad antimicrobiana y perfil de toxicidad de las abejas melíferas del género Melipona Illiger, 1806: Una revisión integradora

\section{Resumo}

Objetivo: Verificar em literatura dados que confirmem as propriedades antimicrobiana e um perfil de toxicidade dos méis de abelha indígena sem ferrão do gênero Melipona. Metodologia: Foi realizado Revisão bibliográfica nas bases de dados: Biblioteca Virtual em Saúde (BVS), PubMed e Google acadêmico. Sendo selecionados artigos, monografias, dissertações e teses, datados entre 2000 a 2020, nos idiomas português e inglês. A busca foi realizada por meio dos descritores: abelhas sem ferrão (Stingless bees), atividade antimicrobiana (Antimicrobian activity), mel (Honey) e toxicidade (Toxicity). E os artigos incompletos, ou que não estiveram dentro da margem temporal préestabelecida, e aqueles duplicados foram excluídos da pesquisa. Resultados: os resultados obtidos foram apresentados em relação as principais espécies do gênero Melipona produtoras de mel, os preponderantes compostos responsáveis pela atividade biológica, além da descrição da atividade antimicrobiana e do perfil de toxicidade dos méis citadas nos arquivos. Conclusão: Constata-se a potencial atividade antimicrobiana dos méis de meliponíneos, graças a pluralidade de compostos químicos e biológicos ativos presentes. Sendo ainda, caracterizado o perfil de toxicidade destes méis, sugerindo como a principal causa dessa condição, a contaminação microbiológica.

Palavras-chave: Abelhas; Atividade antimicrobiana; Mel; Toxicidade.

\begin{abstract}
Objective: To verify in the literature data that confirm the antimicrobial properties and a toxicity profile of stingless indigenous bee hives of the genus Melipona. Methodology: Bibliographic review was carried out in the databases: Virtual Health Library (VHL), PubMed and Google academic. Articles, monographs, dissertations and theses were selected, dated between 2000 and 2020, in Portuguese and English. The search was carried out using the descriptors: stingless bees (Abelhas sem ferrão), antimicrobian activity (Atividade Antimicrobiana), honey (Mel) and toxicity (Toxicidade). And articles that were incomplete, or that were not within the pre-established time margin, and those that were duplicated were excluded from the research. Results: the results obtained were presented in relation to the main honey producing Melipona species, the predominant compounds responsible for biological activity, in addition to the description of the antimicrobial activity and the toxicity profile of the honeys mentioned in the files. Conclusion: The potential antimicrobial activity of the honeysuckle honey is verified, thanks to the plurality of active
\end{abstract}


chemical and biological compounds present. Furthermore, the toxicity profile of these honeys is characterized, suggesting that the main cause of this condition is microbiological contamination.

Keywords: Bees; Antimicrobian activity; Honey; Toxicity.

\begin{abstract}
Resumen
Objetivo: Verificar en la literatura datos que confirmen las propiedades antimicrobianas y un perfil de toxicidad de colmenas de abejas autóctonas sin aguijón del género Melipona. Metodología: Se realizó revisión bibliográfica en las bases de datos: Biblioteca Virtual en Salud (BVS), PubMed y Google académico. Se seleccionaron artículos, monografías, disertaciones y tesis, fechados entre 2000 y 2020, en portugués e inglés. La búsqueda se realizó utilizando los descriptores: abejas sin aguijón (Abelhas sem ferrão), actividad antimicrobiana (Atividade Antimicrobiana), miel (Mel) y toxicidad (Toxicidade). Y los artículos que estaban incompletos, o que no estaban dentro del margen de tiempo preestablecido, y los que estaban duplicados fueron excluidos de la investigación. Resultados: se presentaron los resultados obtenidos en relación a las principales especies del género Melipona productoras de miel, los compuestos predominantes responsables de la actividad biológica, además de la descripción de la actividad antimicrobiana y el perfil de toxicidad de las mieles mencionadas en los expedientes. Conclusión: Se verifica la potencial actividad antimicrobiana de la miel de madreselva, gracias a la pluralidad de compuestos químicos y biológicos activos presentes. Además, se caracteriza el perfil de toxicidad de estas mieles, sugiriendo que la principal causa de esta condición es la contaminación microbiológica.
\end{abstract}

Palabras clave: Abejas; Actividad antimicrobiana; Miel; Toxicidad.

\title{
1. Introdução
}

Os registros fosseis mostram que as primeiras abelhas surgiram há 125 milhões de anos, nas regiões áridas do Oeste de Gondwana, onde as angiospermas se originaram. As abelhas são encontradas hoje em várias regiões áridas, semiáridas e não áridas do mundo. Atualmente existem mais de 500 espécies de abelhas sem ferrão em todo o mundo, porém, a literatura científica demonstra, que é no Brasil que se concentra a maior quantidade de meliponíneos do planeta, principalmente nas regiões Norte e Nordeste do país (Jamil Neto, 2006).

$\mathrm{O}$ etnoconhecimento sobre esses insetos, demostram que a meliponicultura, criação de abelhas indígenas, apresenta características positivas, enfatizando o valor e a importância dessas abelhas no âmbito ecológico e econômico. Essa já vem sendo cultivada há séculos, por povos indígenas, camponeses e agricultores, sendo atribuído a metabolitos melíponas caráter medicamentoso, através de crenças e religiões, informações repassadas de geração a geração. Vislumbrando assim, a popularização e a difusão do conhecimento sobre derivados meliponícolas, dentre eles a própolis, o geoprópolis o pólen ou samburá, a cera e o de maior importância, o mel (Rodrigues, 2005; Silva; Paz, 2012).

Pesquisas mais ativas sobre a biodiversidade de plantas e animais foram realizadas, exemplificando os recursos genéticos e bioquímicos que podem ser modificados ou que possuem moléculas biologicamente ativas com potencial farmacêutico. Ainda que o desenvolvimento de fármacos a partir de recursos naturais seja um processo de extrema complexidade. Embora a maioria dos estudos se concentre na atividade de produtos vegetais, os artigos de origem animais ganharam muito espaço, por exemplo, os obtidos a partir do metabolismo das abelhas, em destaque os méis de abelhas sem ferrão (Teixeira, 2007; Batiston, 2017; Simonetti, 2019).

$\mathrm{O}$ mel é encontrado em consistência líquida, sendo viscoso, aromático e doce, obtido à base de néctar coletado de plantas, no qual abelhas melíferas recolhem, transmudam, associam e deixam maturar nas colmeias. A composição do mel varia de acordo com a espécie de abelha produtora, da origem floral ou fonte de alimento, flutuações no teor de néctar, das condições geográficas e climáticas, isto é, mudanças sazonais, bem como da gestão dos meliponicultores. Também é mencionado que suas propriedades podem ser modificadas de acordo com o tipo de flor utilizada pelo inseto, clima, solo, umidade, altitude, entre outros, afetando o flavor, a cor e o aroma do mesmo. Entre seus constituintes químicos, encontram-se açúcares (glicose, frutose, sacarose, etc), minerais, ácidos orgânicos, enzimas, água e partículas densas procedente da colheita (Venturini; Sarcinelli; Silva, 2007; Batiston, 2017).

Os derivados desses insetos, durante muito tempo, foram considerados como a única fonte disponível de açúcar e com 
capacidade terapêutica ou propedêutica contra determinadas enfermidades, comumente associadas a infecções microbianas. Atribui-lhe importância não só nutricional, como também terapêutica, adjudicadas à medicina popular e/ou à utilização como cosmético. Propriedades como antimicrobiana, antifúngica, antiviral, antiparasitária e anti-inflamatória são propostas a esse derivado animal (Silva; Paz, 2012; Borsato et al., 2013; Rao; Krishnana; Sallehb; Gan, 2016; Batiston, 2017).

Os méis de abelha sem ferrão são produtos que, via atual, alcançam um aumento recente do consumo comercial devido principalmente à prova científica de suas propriedades farmacológicas, sendo as mais diversas peculiaridades terapêuticas atribuídas a este produto. Além das já citadas, há registros literários que fazem alusão a funções cicatrizantes e antioxidantes (Gonçalves; Alves Filho; Menezes, 2005; Pinheiro et al., 2018).

Vista a extensão das características desse produto, é realizada uma classificação do mel para facilitar a amplitude do conhecimento. Sendo variável e, baseada de acordo com a fonte de coleta. Consegue-se assim a divisão em fontes florais ou extraflorais, sendo essa última fundamentada na coleta de melato, ou mel de exsudado, aquele obtido de seivas de certas plantas ou de excreções de insetos sugadores. Já o mel floral é arranjado a partir dos néctares de órgãos reprodutores exclusivos das angiospermas (Felix, 2019).

O mel pode ser classificado de maneira simplificada em monofloral ou inifloral (sua origem é de apenas uma espécie botânica), bifloral (origem de duas espécies botânicas), heterofloral, polifloral ou mel silvestre (várias espécies botânicas) e extrafloral ou mel de exsudado (outras fontes). Essas variações farmacognósticas permitem que esse produto natural apresente atividades benéficas em inúmeras enfermidades. A de destaque, a ação antimicrobiana (Borsato et al., 2013; Rao; Krishnana; Sallehb; Gan, 2016; Grzegozeski, 2015; Batiston, 2017; Felix, 2019).

O mel produzido por meliponíneos é considerado um alimento completo e nutritivo, mas poucos estudos científicos têm foco na caracterização de seus principais compostos químicos associados às propriedades farmacológicas (Venturini; Sarcinelli; Silva, 2007). Várias substâncias tais como fermentos, açúcares, aminoácidos, ácidos orgânicos, diversos elementos químicos, vitaminas e minerais, flavonoides, compostos fenólicos e outros fitoquímicos, enzimas, substâncias bactericidas, aromáticas e pigmentos foram identificadas no mel (Mercês et al., 2013; Pimentel et al., 2013; Nishio et al., 2016; Pinheiro et al., 2018).

A demonstração do potencial antimicrobiano deve levar em consideração que a quantidade desses componentes e esse teórico potencial farmacológico estão relacionados à localização geográfica, condições climáticas e mudanças na fonte alimentar da colmeia durante as estações do ano (Batiston, 2017). Apesar disso, os relatórios sobre a qualidade microbiológica dos méis são raros e a inexistência de uma legislação específica que atue neste cenário, dificulta atribuições a seus aspectos e a determinação da segurança alimentar deste produto (Pinheiro et al., 2018).

Por vezes, os estudos empíricos desses componentes da biodiversidade proporcionam a obtenção de novas substâncias devido à variedade de constituintes químicos que apresentam. Porém, ao mesmo tempo, sabe-se que todo produto natural biologicamente ativo pode apresentar um determinado grau de toxidade, principalmente ao relato da etologia de determinadas espécies animais (Simonetti, 2019).

Neste contexto, verifica-se a vasta utilização desses componentes produzidos pelas abelhas, sendo o mel o principal derivado de destaque para uso terapêutico. Considerando que, dentre as propriedades atribuídas, a atividade antimicrobiana é a que tem despertado maior interesse entre os pesquisadores. Visto a amplitude de aplicação, sendo uma alternativa farmacológica em tratamentos precoces. Porém, ao observar as constantes variações na composição do mel, potencial biológico dos constituintes químicos e a manipulação incoerente de alguns meliponicultores, torna-se discutível, que esse derivado possa apresentar algum grau de toxidade (Gonçalves; Alves Filho; Menezes, 2005; Silva; Paz, 2012).

Sendo assim, os estudos, ao relacionar informações sobre as observações citadas anteriormente, auxiliariam a sociedade científica e a população geral no desenvolvimento de uma melhor concepção farmacológica e toxicológica dos méis 
de abelhas sem ferrão, quando utilizado com a finalidade terapêutica. Podendo levar, por meio de estudos futuros, a determinação da frequência de administração e duração de tratamento, quando aplicado como terapia. Porém, as pesquisas científicas relacionadas ao tema são incipientes. Há perspectiva de desenvolvimento de novos estudos sobre os méis de abelhas sem ferrão nas mais diversas áreas, principalmente em processos técnico e científico (Venturini; Sarcinelli; Silva, 2007).

Assim, dado o cenário atual, com o uso indiscriminado de medicamentos antimicrobianos (produção animal, ambulatorial ou hospitalar e doméstico) e o surgimento de agentes resistentes a essas classes farmacológicas, bem como a possibilidade de descobrir novos medicamentos por meio de observação empírica, observa-se que os produtos naturais podem ter uma relevância significativa como alternativa terapêutica para infecções microbianas. Os méis produzidos pelas abelhas sem ferrão, nessa perspectiva, as do gênero Melipona, constituem uma boa fonte de estudo, pois possuem poucas características físico-químicas e microbiológicas conhecidas, e vista a distribuição geográfica desses animais pelo Brasil (Batiston, 2017).

Diante do apresentado, o objetivo do presente trabalho foi voltado para verificar em literatura, informações que confirmem as propriedades antimicrobiana e um perfil de toxicidade dos méis de abelha indígena sem ferrão do gênero Melipona. Além, de identificar as principais espécies de abelhas deste gênero produtoras de mel e realizar um levantamento dos principais constituintes químicos e/ou biológicos associados às propriedades farmacológicas antimicrobianas.

\section{Metodologia}

A pesquisa realizada é uma revisão bibliográfica, do tipo qualitativa e descritiva, a qual foi realizada busca de dados bibliográficos nas bases científicas: Biblioteca Virtual em Saúde (BVS), PubMed e Google acadêmico. Foram selecionados artigos publicados entre 2000 a 2020, nos idiomas português e inglês. Como critérios de inclusão para o trabalho, apenas artigos completos e que melhores se enquadrarem na temática abordada. E exclusos da pesquisa, os artigos incompletos, os que não estiveram dentro da margem temporal pré-estabelecida e os duplicados. A busca foi norteada pela utilização dos termos: abelhas sem ferrão (stingless bees), atividade antimicrobiana (antimicrobian activity), mel (honey) e toxicidade (toxicity). Com isso, analisou-se pesquisas clínicas, artigos de revisão, monografias, dissertações e teses. As palavras-chaves selecionadas estão de acordo com DeCS (Descritores em Ciências da Saúde).

\section{Revisão da literatura}

\subsection{A real importância das abelhas indígenas sem ferrão}

As abelhas da subfamília Meliponinae (Hymenoptera, Apidae) são relacionadas como abelhas nativas sem ferrão ou ainda meliponídeos, assim denominadas por apresentarem o ferrão atrofiado. São animais sociais, dóceis, de fácil manejo e necessitam de pouco investimento para a sua criação, sendo de ampla distribuição geográfica no Brasil, referindo-se a mais de 400 espécies, distribuídas em 27 gêneros de invertebrados (Silva et al., 2016).

Esses animais se adaptaram geograficamente à regionalidade do clima e da alimentação e se caracterizam por serem silvestres e nativos do território brasileiro. Possuem uma resolução do Conselho Nacional do Meio Ambiente (CONAMA) n ${ }^{\circ}$ 346, de 16 de agosto de 2004, que se refere ao registro do meliponicultor e o transporte das espécies para fora de suas respectivas áreas de distribuição geográfica original (Brasil, 2004; Batiston, 2017).

Apresentam importância ambiental, econômica e social dentro de diversos nichos e regiões onde ocorrem sua presença. Como benefícios ambientais, cita-se a restauração e preservação de florestas tropicais, disseminação sexual de angiospermas, que auxiliam na produção e manutenção alimentícia, além da conservação das redes de interações entre espécies botânicas e animais. Funcionam, ainda, como bioindicadoras da qualidade ambiental (Silva; Paz, 2012). 
Já em complacência socioeconômica, desempenham papel como atividade complementar de uma criação racional mais produtiva, uma vez que o interesse comercial vem crescendo pela procura dos subprodutos, tais como mel, cera, pólen, própolis e geoprópolis, sendo bastante valorizados, economicamente. Evidencia que, em relação ao gênero Apis, abelhas tipicamente com ferrão, a produção de méis de abelhas sem ferrão é relativamente subexplorada, em função da falta de uma legislação específica e de um controle de qualidade próprio para estes tipos de produtos, que são condizentes como necessidades para sua comercialização (Venturini; Sarcinelli; Silva, 2007).

Os hábitos e comportamentos tradicionais relacionados à gestão desses animais são ratificados, registrados e avaliados ao longo dos séculos por várias civilizações, como povos indígenas, comunidades tradicionais, camponeses e agricultores. As abelhas nativas desempenharam e continuam a desempenhar um papel importante na dieta, religião, mitos, rituais, crenças, bem como na medicina de vários povos do mundo. Mas, entre todos os produtos meliponícolas, o mel sempre foi o produto mais valioso por suas propriedades curativas (Teixeira, 2007; Dutra et al., 2008; Silva; Paz, 2012; Felix, 2019).

Dentre os efeitos biológicos terapêuticos deste derivado, evidencia em revisão literária, singularidade atribuída à eficácia clínica nas mais diversas enfermidades, dentre essas, antimicrobianas, antioxidantes, antidiabético, anti-inflamatórias, anticancerígenas, anti-hiperlipidêmicas ou hipolipidêmico, cardioprotetoras, hepatoprotetora, tratamento de distúrbios oculares, doenças do trato gastrointestinal, distúrbios neurológicos e de fertilidade, atividade de cicatrização de feridas e problemas da tireoide (Pimentel et al., 2013; Nishio et al., 2016; Rao; Krishnana; Sallehb; Gan, 2016; Pinheiro et al., 2018).

Apesar da existência de uma vasta bibliografia sobre diversos aspectos das abelhas sem ferrão brasileiras, ainda é pouca a disseminação sobre o conhecimento das espécies e seus derivados metabólicos, demonstrando que a importância dos meliponíneos supera aspectos sociais, econômicos e ecológicos, tendo enfoque atual no campo científico, como a entomoterapia (Dutra et al., 2008).

\subsection{Entomofagia e entomoterapia}

A entomofagia é um evento com traços ancestrais e amplamente difundido geograficamente. E por definição, retrata o consumo de insetos por humanos, estes como fonte de alimento. Visto que a fome possivelmente será um dos maiores desafios que a humanidade encarará no futuro. A entomofagia vem para subsidiar uma alternativa a alimentação humana. Cerca de 120 países ao redor do globo apresentam a entomofagia como hábito, costume ou em rituais por crenças. Já foram descritas mais de 750 mil espécies vivas de insetos, e dessas, cerca de 1700 são utilizadas como alimento por aproximadamente três mil grupos étnicos (Costa-Neto; Resende, 2004; Romeiro; Oliveira; Carvalho, 2015).

Curiosamente, no Brasil, constata-se que é praticamente impossível remover todos os insetos das plantas que são cultivadas ano após anos. Tendo em vista isso, a Agência Nacional de Vigilância Sanitária (ANVISA), apresenta uma resolução, RDC nº 14 de 28 de março de 2014, que dispõem sobre matérias estranhas macroscópicas e microscópicas em alimentos e bebidas, seus limites de tolerância e dá outras providências. Por conta desta, a Anvisa tolera certa quantidade de fragmentos de insetos nos alimentos. Isso é possível, uma vez que não a risco de transmissão de doenças ou intoxicação, pois, a tolerância não é válida para patógenos (Brasil, 2014).

A entomoterapia por sua vez, é o ramo da zooterapia que visa a cura ou tratamento de doenças pela ingestão de insetos, partes destes ou seus metabolitos. Muito observada na medicina empírica e atualmente estudada para confirmação cientificas das mais diversas terapias citadas pela medicina popular. Esses estudos se justificam uma vez que visam a obtenção de compostos farmacológicos que promovem o desenvolvimento de novas drogas e garantam melhoria da saúde humana (Costa-Neto; Pacheco, 2005).

De acordo com a Food and Agriculture Organization of the United Nations (FAO) ou Organização das Nações Unidas para Agricultura e Alimentação, mais de 2 bilhões de pessoas em todo o mundo já complementa suas dietas com 
insetos. Visto isso, os produtos oriundos das abelhas, tais como cera, pólen, própolis, geoprópolis e em destaque o mel, também são significativamente importantes (Silva; Paz, 2012; Romeiro; Oliveira; Carvalho, 2015).

Citando até mesmo como referência da importância da utilização desses metabolitos para a saúde, o contexto da etimologia. A palavra medicina tem sua ascendência ao termo mel, pois a primeira sílaba tem a mesma raiz que mead, ou hidromel, bebida alcoólica feita dos favos de abelhas e que era consumida frequentemente como elixir tônico (Costa-Neto; Pacheco, 2005).

Assim, cita-se que os meliponíneos apresentam produtos e subprodutos bastante valorizados economicamente, tendo o mel, como principal produto de exploração, por suas características nutricionais e terapêuticas, em destaque a atividade antimicrobiana. Diante disso e de uma procura cada vez maior por produtos naturais, há a necessidade de intensificar as pesquisas para se identificar a qualidade destes produtos, e assim garantindo um consumo sem danos à saúde. Como também as formas adequadas de preparo e conservação (Romeiro; Oliveira; Carvalho, 2015).

\subsection{Caracterização das abelhas do gênero Melipona}

A classificação geral das abelhas de mel sem ferrão para o Brasil é baseada em duas propostas: a catalogação de Michener (2000), valendo-se da tribo Meliponini e a de Silveira et al. (2002), empregando subtribo Meliponina. Considerando essas propostas, são relacionadas taxonomicamente em: Ordem: Hymenoptera; Subordem: Apócrita; Superfamília: Apoidea; Série: Apiformes; Família: Apidae; Subfamília: Apinae; Tribo: Apini e Subtribo: Meliponina (Jamil Neto, 2006).

Os insetos constituem aproximadamente $53 \%$ do total de taxa de todas as espécies biológicas, representando $4 / 5$ do reino animal. Atualmente são descritas 16.000 espécies de abelhas. Para o Brasil, calcula-se a existência de 3.000, e quando direcionado às abelhas indígenas, consta com uma composição de fauna de 619 espécies presentes no país (Sanches, 2012). É perceptível que entre as abelhas sem ferrão, o gênero Melipona é o de maior notoriedade, tendo em vista que os metabólitos produzidos por essas espécies têm possibilidade de aplicação na indústria farmacêutica e alimentícia, sendo conhecido pelo menos 40 espécies deste grupo (Lima; Silvestre, 2017).

Esse gênero se caracteriza por espécies de abelhas com diversidades biológicas e adaptações morfológicas, fisiológicas e comportamentais. Apresentam a vantagem de serem sociáveis, podendo ser criadas e domesticadas pelo homem, isto é, criação racional ou manejo. São predominantemente da região geográfica latino-americana, em territórios tropicais e subtropicais, e mais raramente regiões temperadas. Apresentando espécies endêmicas do país, por mais que convencionalmente, a sua amestração seja conferida à sociedade mesoamericana dos Maya (Teixeira, 2007).

As colônias geralmente são permanentes e apresentam numerosos exemplares (variação entre poucas dúzias a 100.000 ou mais operarias). Essas abelhas são consideradas generalistas, uma vez que exploram um amplo espectro floral, que geram maiores benefícios tróficos. Os meliponíneos apresentam porte de tamanho variável (pequeno, médio e grande ou avantajado, a variação é entre $6 \mathrm{~mm}$ e $15 \mathrm{~mm}$ de comprimento), este último de maior relevância, pois teoricamente, proporcionaria coletas mais satisfatórias de mel. As intitulações mais comuns atribuídas a esses animais são "abelhas indígenas ou nativas", referente a domesticação destas pelos indígenas em território brasileiro, motivo pelo qual muitas de suas denominações comuns, têm origem tupi (Teixeira, 2007; Silva; Paz, 2012).

São abelhas inaptas a ferroar, pois esse órgão, ferrão (ovipositor modificado para injeção de veneno), encontra-se atrofiado. Sendo o comportamento comum, o eussocial. Apesar de algumas espécies serem cleptoparasitas. A nidificação é constante em cavidades ou depressões pré-existentes, e a organização estrutural da entrada do ninho e da colmeia, auxilia na identificação da espécie. Sendo comum das abelhas sem ferrão a utilização de geoprópolis (resina a base de barro e própolis) para encauchar o ninho. Outra curiosidade bastante interessante é que a capacidade de voo é diferente para cada espécie, e pode variar de 600 a 2.400 metros, dependo do tamanho do corpo do inseto (Silva; Paz, 2012). 
Embora os animais de destaque englobem somente as espécies do gênero Melipona, não é descartada a ideia da criação de abelhas sem ferrão de outras espécies. Pelo contraio, é até mesmo incentivada. Uma vez que pode proporcionar aspectos positivos nos meios econômico, social, ecológico, político, cultural e ética da sustentabilidade. Alcançando agricultura sustentável mais produtiva que agrega valor ao produto a ser explorado (Teixeira, 2007; Lima; Silvestre, 2017).

De acordo com a Empresa Brasileira de Pesquisa Agropecuária (Embrapa), apesar de se ter a compreensão da existência de mais de 300 espécies de abelhas nativas, apenas uma pequena quantidade destas são indicadas e propícias a meliponicultura. Sendo que as espécies frequentemente indicadas para a produção de mel são: Melipona scutellaris, Melipona fasciculata, Melipona subnitida, Melipona manaosensis, Melipona quadrifasciata anthidioides e Tetragonisca angustula (Pereira; Souza; Lopes, 2017).

E é importante ressaltar que a meliponicultura tem uma visão ecológica, onde o meliponicultor deve manejar as suas criações com princípios de preservação do meio natural. Uma vez que se trata de animais que se encontram fortemente ameaçados, por prejuízos ao ecossistema ondem habitam, e predação por meleiros. Assim deve-se criar apenas espécies de abelhas particulares de sua região, e não é recomendado a introdução de espécies oriundos de outras áreas. Sendo aconselhável ao responsável pelo meliponário, ampliar e fortalecer sua criação, havendo sempre que possível a multiplicação das colônias. Essas medidas permitem ajustar o sistema de criação de abelhas sem ferrão, evitando coletas de colméias de abelhas em trocos e ocos de árvores na natureza (Teixeira, 2007).

Prosseguindo com o trabalho e tendo em vista que a meliponicultura é uma atividade bastante empregada nas regiões Norte e Nordeste do Brasil, relaciona-se as principais espécies utilizadas neste ramo, baseada na criação dos meliponicultores dessas áreas geográficas, que foram relacionadas no a seguir.

Quadro 1 - Nome científico, popular e autor do estudo onde foi citada, das espécies de abelhas sem ferrão do gênero Melipona comumente encontradas no Brasil:

\begin{tabular}{|c|c|c|}
\hline NOME CIENTÍFICO & NOME POPULAR & AUTOR \\
\hline Melipona asilvai (Moure, 1971) & Munduri ou Rajada. & $\begin{array}{c}\text { Obiols, 2008; } \\
\text { Silva; Paz, 2012; } \\
\text { Sousa } \text { et al., 2013; } \\
\text { Cabral, 2014; } \\
\text { Pereira; Souza; Lopes, } 2017 .\end{array}$ \\
\hline $\begin{array}{c}\text { Melipona beecheii (Bennett , } \\
\text { 1831) }\end{array}$ & Xunan kab -“Abelha real” & $\begin{array}{c}\text { Lima, } 2004 . \\
\text { Cruz, et al. } 2014 ; \\
\text { Zamora } \text { et al., } 2017 .\end{array}$ \\
\hline $\begin{array}{l}\text { Melipona (Michmelia) dubia } \\
\text { (Moure \& Kerr, 1950) }\end{array}$ & $\begin{array}{l}\text { Guaraipo-amarela, Uruçu-amarela, } \\
\text { Tuiuva, Tujuba ou Bugia. }\end{array}$ & Lima, 2004. \\
\hline $\begin{array}{l}\text { Melipona favosa favosa } \\
\text { (Fabricius, 1798) }\end{array}$ & Monduri do Mato Grosso & $\begin{array}{c}\text { Lima, 2004; } \\
\text { Cabral, 2014; } \\
\text { Rao et al., 2016; } \\
\text { Brown et al., 2020. }\end{array}$ \\
\hline $\begin{array}{c}\text { Melipona (Michmelia) } \\
\text { brachychaeta (Moure, 1950) }\end{array}$ & Jandaíra ou Erereú-choca & $\begin{array}{c}\text { Lima, 2004; } \\
\text { Lima; Silvestre, } 2017 .\end{array}$ \\
\hline
\end{tabular}




\begin{tabular}{|c|c|c|}
\hline $\begin{array}{c}\text { Melipona fasciculata (Smith, } \\
\text { 1854) }\end{array}$ & Tiúba ou Uruçu-cinzenta. & $\begin{array}{c}\text { Venturieri; Raiol; Pereira, 2003; } \\
\text { Jamil Neto, 2006; } \\
\text { Venturieri; Oliveira; Vasconcelos; Mattietto, 2007; } \\
\text { Venturieri, 2008; } \\
\text { Dutra } \text { et al. 2008; } \\
\text { Martins; Rêgo; carreira; Albuquerque, 2011; } \\
\text { Holanda et al., 2012; } \\
\text { Silva; Paz, 2012; } \\
\text { Sousa } \text { et al., 2013; } \\
\text { Cabral, 2014; } \\
\text { Rao } \text { et al., 2016; } \\
\text { Silva } \text { et al., 2016; } \\
\text { Pereira; Souza; Lopes, 2017; } \\
\text { Jalil; Kasmuri; Hadi, 2017; } \\
\text { Fernandes; Rosa; Conti-Silva, 2018. }\end{array}$ \\
\hline $\begin{array}{l}\text { Melipona quadrifasciata } \\
\text { anthidioides (Lepeletier, 1836) }\end{array}$ & Mandaçaia. & $\begin{array}{c}\text { Lima, 2004; } \\
\text { Rodrigues, 2005; } \\
\text { Dutra et al. 2008; } \\
\text { Obiols, 2008; } \\
\text { Sousa, 2008; } \\
\text { Fernesi } \text { et al., 2009; } \\
\text { Martins; Rêgo; Carreira; Albuquerque, 2011; } \\
\text { Silva; Paz, 2012; } \\
\text { Sousa } \text { et al., 2013; } \\
\text { Borsato } \text { et al., 2013; } \\
\text { Cabral, 2014; } \\
\text { Grzegozeski, 2015; } \\
\text { Silva, 2016; } \\
\text { Pereira; Souza; Lopes, 2017; } \\
\text { Bonamigo } \text { et al., 2017; } \\
\text { Batiston, 2017; } \\
\text { Fernandes; Rosa; Conti-Silva, 2018; } \\
\text { Ávila } \text { et al., 2019. }\end{array}$ \\
\hline $\begin{array}{c}\text { Melipona quadrifasciata } \\
\text { quadrifasciata (Lepeletier, 1836) }\end{array}$ & Mandaçaia. & $\begin{array}{c}\text { Lima, 2004; } \\
\text { Rodrigues, 2005; } \\
\text { Obiols, 2008; } \\
\text { Fernesi } \text { et al., 2009; } \\
\text { Martins; Rêgo; Carreira; Albuquerque, 2011; } \\
\text { Silva; paz, 2012; } \\
\text { Borsato } \text { et al., 2013; } \\
\text { Grzegozeski, 2015; } \\
\text { Silva, 2016; } \\
\text { Pereira; Souza; Lopes, 2017; } \\
\text { Batiston, 2017; } \\
\text { Fernandes; Rosa; Conti-Silva, 2018; } \\
\text { Barcelos; Harter-Marques, 2019; } \\
\text { Avvila } \text { et al., 2019; }\end{array}$ \\
\hline $\begin{array}{l}\text { Melipona quinquefasciata } \\
\text { (Lepeletier, 1836) }\end{array}$ & $\begin{array}{l}\text { Mandaçaia-do-chão ou Uruçu-do- } \\
\text { chão. }\end{array}$ & $\begin{array}{c}\text { Lima, 2004; } \\
\text { Obiols, 2008; } \\
\text { Silva; Paz, 2012; } \\
\text { Sousa et al., 2013; } \\
\text { Lima; Silvestre, 2017. }\end{array}$ \\
\hline $\begin{array}{l}\text { Melipona (Michmelia) seminigra } \\
\text { aff merrillae (Cockerell, 1919) }\end{array}$ & $\begin{array}{l}\text { Jandaíra alaranjada ou Uruçu-boca- } \\
\text { de-renda. }\end{array}$ & $\begin{array}{c}\text { Jamil neto, 2006; } \\
\text { Sousa, 2008; } \\
\text { Silva; Paz, 2012; } \\
\text { Oliveira et al..2013; } \\
\text { Cruz, } \text { et al. 2014; } \\
\text { Venturieri, 2008; } \\
\text { Pereira; Souza; Rao et al., 2016; } \\
\text { Lopes, 2017; } \\
\text { Domingos, 2019; } \\
\text { Domingos } \text { et al., 2020. }\end{array}$ \\
\hline $\begin{array}{c}\text { Melipona (Eomelipona) } \\
\text { puncticollis (Friese, 1902) }\end{array}$ & Uruçu-amarela-preguiçosa. & Venturieri, 2008. \\
\hline Melipona subnitida (Ducke, 1910) & Jandaíra. & $\begin{array}{c}\text { Silva; Paz, 2012; } \\
\text { Sousa et al., 2013; } \\
\text { Cabral, 2014; } \\
\text { Cruz, et al. 2014; } \\
\text { Campêlo et al., 2015. } \\
\text { Rao et al., 2016; }\end{array}$ \\
\hline
\end{tabular}


Research, Society and Development, v. 10, n. 4, e13510413903, 2021

(CC BY 4.0) | ISSN 2525-3409 | DOI: http://dx.doi.org/10.33448/rsd-v10i4.13903

\begin{tabular}{|c|c|c|}
\hline & & $\begin{array}{c}\text { Silva } \text { et al., 2016; } \\
\text { Pereira; Souza; Lopes, 2017; } \\
\text { Batiston, 2017; } \\
\text { Fernandes; Rosa; Conti-Silva, 2018; } \\
\text { Pinheiro et al., 2018; } \\
\text { Ávila } \text { et al., 2019. }\end{array}$ \\
\hline $\begin{array}{l}\text { Melipona. flavolineata (Smith, } \\
\text { 1858) }\end{array}$ & Uruçu-amarela. & $\begin{array}{c}\text { Lima, 2004; } \\
\text { Venturieri; Oliveira; } \\
\text { Vasconcelos; Mattietto, 2007; } \\
\text { Venturieri, 2008; } \\
\text { Pereira; Souza; Lopes, 2017; } \\
\text { Domingos, 2019; } \\
\text { Domingos } \text { et al., 2020. }\end{array}$ \\
\hline $\begin{array}{c}\text { Melipona (Eomelipona) illustris } \\
\text { (Schwarz, 1932) }\end{array}$ & $\begin{array}{l}\text { Não há registro na literatura de } \\
\text { nomes populares para esta espécie. }\end{array}$ & Oliveira et al.,2013. \\
\hline $\begin{array}{c}\text { Melipona (Eomelipona) schwarzi } \\
\text { (Moure, 1963) }\end{array}$ & $\begin{array}{l}\text { Não há registro na literatura de } \\
\text { nomes populares para esta espécie. }\end{array}$ & Oliveira et al.,2013. \\
\hline $\begin{array}{c}\text { Melipona (Melikerria) grandis } \\
\text { (Guérin, 1834) }\end{array}$ & $\begin{array}{c}\text { Uruçu preta ou preto, Uruçu- } \\
\text { cinzento, Guare, Patchumepube, } \\
\text { Buná-bissu, Rajadinho-maior ou } \\
\text { Preto-maior. }\end{array}$ & $\begin{array}{l}\text { Jamil Neto, 2006; } \\
\text { Oliveira et al.,2013; } \\
\text { Domingos, 2019; } \\
\text { Domingos } \text { et al., 2020. }\end{array}$ \\
\hline $\begin{array}{l}\text { Melipona (Michmelia) crinita } \\
\quad \text { (Moure \& Kerr, 1950) }\end{array}$ & $\begin{array}{l}\text { Uruçu-amarela-avermelhada, } \\
\text { Jandaíra-maior, Maria-preguiçosa, } \\
\text { Uruçu-vermelha, Buná-bissu- } \\
\text { tashipaki, Uruçu-amarela, Uruçu- } \\
\text { avermelhada, Uruçu-amarela } \\
\text { avermelhada ou Jandaíra. }\end{array}$ & $\begin{array}{l}\text { Jamil Neto, 2006; } \\
\text { Oliveira et al.,2013. }\end{array}$ \\
\hline $\begin{array}{c}\text { Melipona (Michmelia) fuliginosa } \\
\text { (Lepeletier, 1836) }\end{array}$ & $\begin{array}{c}\text { Uruçu-boi; Curruncho grande; } \\
\text { Uruçu preto, Uruçu, Erereú-negra, } \\
\text { Mel-de-anta, Nara-buná-bisuki, } \\
\text { Erereú-negra; Sucuasue ou Tapir } \\
\text { bee. }\end{array}$ & $\begin{array}{l}\text { Jamil Neto, 2006; } \\
\text { Oliveira et al.,2013. }\end{array}$ \\
\hline $\begin{array}{c}\text { Melipona (Michmelia) paraensis } \\
\text { (Ducke, 1916) }\end{array}$ & $\begin{array}{l}\text { Jandaíra, Uruçu amarelo, Uruçu } \\
\text { amarela do Pará, Uruçu-bocade-ralo } \\
\text { e Me-tekere. }\end{array}$ & $\begin{array}{l}\text { Lima, 2004; } \\
\text { Jamil Neto, 2006; } \\
\text { Oliveira et al.,2013. }\end{array}$ \\
\hline Melipona mondury (Smith 1863) & Monduri & $\begin{array}{c}\text { Lima, 2004; } \\
\text { Obiols, 2008; } \\
\text { Grzegozeski, 2015; } \\
\text { Pereira; Souza; Lopes, 2017; } \\
\text { Batiston, 2017. } \\
\end{array}$ \\
\hline Melipona orbigni (Guérin 1844) & $\begin{array}{c}\text { Mandaçaia ou Monduri do Mato } \\
\text { Grosso }\end{array}$ & $\begin{array}{l}\text { Cabral, 2014; } \\
\text { Bonamigo et al., 2017; } \\
\text { Lima; Silvestre, } 2017 .\end{array}$ \\
\hline $\begin{array}{l}\text { Melipona (Eomelipona) marginata } \\
\text { obscurior (Moure, 1971) }\end{array}$ & $\begin{array}{l}\text { Monduri de-palo, Mondori, } \\
\text { Monduri Guasú e Yurú-apati. }\end{array}$ & Lima; Silvestre, 2017. \\
\hline $\begin{array}{c}\text { Melipona compressipes (Fabricius, } \\
\text { 1804) }\end{array}$ & Tiúba & $\begin{array}{l}\text { Venturieri, 2008; } \\
\text { Sousa, 2008; } \\
\text { Dutra } \text { et al. 2008; } \\
\text { Silva; Paz, 2012; } \\
\text { Cabral, 2014; } \\
\text { Cruz, } \text { et al. 2014; } \\
\text { Silva } \text { et al., 2016; } \\
\text { Pereira; Souza; Lopes, 2017; } \\
\text { Batiston, 2017. }\end{array}$ \\
\hline $\begin{array}{c}\text { Melipona compressipes } \\
\text { manaosensis (Schwarz, 1932) }\end{array}$ & Jupará. & $\begin{array}{c}\text { Jamil neto, 2006; } \\
\text { Venturieri, 2008; } \\
\text { Sousa, 2008; } \\
\text { Dutra } \text { et al. 2008; } \\
\text { Silva; paz, 2012; } \\
\text { Cabral, 2014; } \\
\text { Pimentel; Costa; Albuquerque; Duvoisin Junior, 2013; } \text {; al. 2014; } \\
\text { Cruz, } \\
\text { Pereira; Souza; Lopes, 2017; } \\
\text { Batiston, 2017. }\end{array}$ \\
\hline $\begin{array}{c}\text { Melipona (Michmelia) seminigra } \\
\text { aff. pernigra (Moure \& Kerr, } \\
1950)\end{array}$ & Taquaruçu. & $\begin{array}{l}\text { Venturieri, 2008; } \\
\text { Oliveira et al.,2013; }\end{array}$ \\
\hline
\end{tabular}




\begin{tabular}{|c|c|c|}
\hline $\begin{array}{c}\text { Melipona scutellaris (Latreille } \\
\text { 1811) }\end{array}$ & $\begin{array}{l}\text { Uruçu verdadeira, Uruçu ou Uruçu- } \\
\text { nordestina. }\end{array}$ & $\begin{array}{c}\text { Rodrigues } \text { et al, 2005; } \\
\text { Costa-Neto; Pacheco, 2005; } \\
\text { Sousa, 2008; } \\
\text { Silva; Paz, 2012; } \\
\text { Sousa } \text { et al., 2013; } \\
\text { Cabral, 2014; } \\
\text { Silva } \text { et al., 2016; } \\
\text { Pereira; Souza; Lopes, 2017; } \\
\text { Fernandes; Rosa; Conti-Silva, 2018; } \\
\text { Bonsucesso } \text { et al., 2018; } \\
\text { Felix, 2019; } \\
\text { Dorigo } \text { et al., 2019. }\end{array}$ \\
\hline $\begin{array}{c}\text { Melipona marginata (Lepeletier, } \\
1836)\end{array}$ & Manduri ou Guaraipo. & $\begin{array}{c}\text { Lima, 2004; } \\
\text { Rodrigues, 2005; } \\
\text { Sousa, 2008; } \\
\text { Obiols, 2008; } \\
\text { Silva; Paz, 2012; } \\
\text { Borsato } \text { et al., 2013; } \\
\text { Cabral, 2014; } \\
\text { Rao et al., 2016; } \\
\text { Batiston, 2017; } \\
\text { Ávila } \text { et al., 2019. }\end{array}$ \\
\hline Melipona mandacaia (Smith 1863) & Mandaçaia ou Mandaçaia-menor & $\begin{array}{c}\text { Silva; paz, 2012; } \\
\text { Sousa } \text { et al., 2013; } \\
\text { Bárbara } \text { et al., 2015; } \\
\text { Pereira; Souza; Lopes, } 2017 .\end{array}$ \\
\hline $\begin{array}{l}\text { Melipona bicolor bicolor } \\
\quad \text { (Lepeletier, 1836) }\end{array}$ & Guaraipo ou Guarupu. & $\begin{array}{c}\text { Lima, 2004; } \\
\text { Rodrigues, 2005; } \\
\text { Sousa, 2008; } \\
\text { Obiols, 2008; } \\
\text { Silva; Paz, 2012; } \\
\text { Borsato et al., 2013; } \\
\text { Cabral, 2014; } \\
\text { Grzegozeski, 2015; } \\
\text { Pereira; Souza; Lopes, 2017; } \\
\text { Batiston, 2017; } \\
\text { Ávila et al., 2019; }\end{array}$ \\
\hline $\begin{array}{c}\text { Melipona rufiventris (Lepeletier, } \\
1836 \text { ) }\end{array}$ & $\begin{array}{c}\text { Uruçu amarela, Tujuba, Tuiuva ou } \\
\text { Tujuva. }\end{array}$ & $\begin{array}{c}\text { Lima, 2004; } \\
\text { Jamil Neto, 2006; } \\
\text { Sousa, 2008; } \\
\text { Obiols, 2008; } \\
\text { Silva; Paz, 2012; } \\
\text { Borsato et al., 2013; } \\
\text { Cabral, 2014; } \\
\text { Pereira; Souza; Lopes, 2017; } \\
\text { Batiston, 2017; } \\
\text { Lima; Silvestre, 2017. }\end{array}$ \\
\hline Melipona ebúrnea (Friese, 1900) & Uruçu-beiço & Domingos, 2019. \\
\hline $\begin{array}{c}\text { Melipona (Michmelia) trinitatis } \\
\text { (Cockerell, 1919) }\end{array}$ & Guanota ou Moca grande & Brown et al., 2020. \\
\hline Melipona eburnea (Friese 1900) & Uruçu Beiço & Domingos et al., 2020. \\
\hline
\end{tabular}

Fonte: Autores (2021).

O gênero Melipona é numericamente grande, até mesmo maior do que a da abelha comum (Apis spp.), no Quadro 01, estão relacionadas 28 espécies de abelha do gênero, que foram encontrados em literatura estudada. Essas informações se comparadas as da Embrapa, entram em consonância, uma vez que de acordo com a empresa, as principais espécies de abelhas do gênero Melipona indicadas para a produção de mel são: Melipona scutellaris, Melipona fasciculata, Melipona subnitida, Melipona manaosensis e Melipona quadrifasciata anthidioides, sendo essas as mais estudadas (Pereira; Souza; Lopes, 2017).

É importante ressaltar que há uma significativa perplexidade e discordância em relação aos títulos populares dos meliponíneos. Isso decorre pois considera-se novas espécies enquadradas em grupos sob revisão, além de haver variações linguísticas regionais (Silva; Paz, 2012; Lima; Silvestre, 2017).

\subsection{Atividade antimicrobiana de méis}

Como descrito, os méis são produtos animais com alta concentração de elementos químicos com atividade biológica significativa, cujas propriedades ou funções terapêuticas são conhecidas há séculos e foram utilizadas por inúmeras 
civilizações, como egípcios, gregos, romanos, assírios, persas e chineses, com finalidade paliativa de inúmeras enfermidades. A comunidade científica, utilizando-se de conhecimentos empíricos e equipamentos sofisticados, tem aprimorado pesquisas direcionadas a esses metabolitos, presumindo alto potencial medicinal, principalmente para desempenhar ações farmacológicas contra microrganismos patogênicos, ressaltando como principais agentes as bactérias e fungos etiológicos (Rao; Krishnana; Sallehb; Gan, 2016).

A propriedade antimicrobiana dos méis foi sugerida por volta de 1800 por estudiosos. No entanto, a descoberta do primeiro antibiótico pelo médico inglês Alexander Fleming, no início dos anos de 1900, induziu uma pesquisa cada vez mais ativa em buscas dessas substâncias, e desviou o interesse científico pelo mel (Batiston, 2017).

O mel é um alimento produzido por abelhas melíferas, elaborado a partir de néctar ou de melato. É respaldado pela Instrução Normativa $\mathrm{N}^{\circ} 11$ de 20 de outubro de 2000 que traz a definição desse derivado apícola e padroniza o processamento dos produtos de origem animal, neste caso especificamente, abelhas da espécie Apis mellifera (Cabral, 2014). Por vez, méis de abelha sem ferrão não apresentam uma legislação especifica, porém, as literaturas sugerem que estes podem ser encontrados em estado líquido, raramente tende ao cristalizado, por apresentar elevada umidade (25 a 35\%), tornando-os menos densos. São produzidos em menor quantidade e a sua cor fugazmente é variável, passando de incolor a pardo-escura, sendo o flavor e eflúvio de acordo com a origem (Brasil, 2000; Borsato et al., 2013).

Os méis de abelhas sem ferrão apresentam uma vasta constituição, nos quais aproximadamente 200 compostos são elencados, tendo os açúcares como predominantes, chegando a atingir 95 a 99\% da constituição do mel. Para exemplificar melhor, glicose, sacarose, maltose, maltotriose, panose e frutose são exemplos clássicos, sendo este último, o monossacárido preponderante, chegando a 32-38\% da composição. Por considerar que os méis em todo o mundo contêm tipos semelhantes de compostos, propõe-se a existência de ácidos orgânicos, como ácidos fenólicos, a citar o elágico, cafeico, p-cumárico e ferúlico; alguns flavonóides, tais como galangina, hesperetina, crisina, apigenina, quercetina, kaempferol e pinocembrina; e antioxidantes, como ácido ascórbico, tocoferóis, glutationa reduzida (GSH), catalase (CAT) e superóxido dismutase (SOD) (Borsato et al., 2013; Rao; Krishnana; Sallehb; Gan, 2016; Batiston, 2017).

Diversos outros elementos orgânicos são citados, aos quais estão inclusas as vitaminas como ácido ascórbico (vitamina C), ácido pantotênico (vitamina B5), tiamina (vitamina B1), biotina (vitamina B8), riboflavina (vitamina B2), piridoxina (vitamina B6), ácido nicotínico (vitamina B3), cianocobalamina (vitamina B12) e o ácido fólico (vitamina B9). Há, também, presença de minerais ou oligoelementos, como sódio, cálcio, potássio, fósforo, magnésio, ferro, sulfureto, manganês, cobre e zinco, além de apresentarem outros fitoquímicos, como enzimas, substâncias bactericidas, aromáticas e pigmentos (Borsato et al., 2013; Cabral, 2014; Rao; Krishnana; Sallehb; Gan, 2016).

Alguns estudos especificam a atividade antimicrobiana dos méis a determinadas substâncias, dentre elas o peróxido de hidrogênio (PH), metil-glioxal (MGO), hidroximetilfurfural (HMF), ácidos fenólicos, flavonóides e defensinas, como principais agentes antibacterianos e antifúngicos. Essa última propriedade é evidenciada nas bibliografias como menos eficaz, fato que se deve principalmente pelo início de ação retardado, ocasionado pela necessidade de entrada das substâncias ativas nas células fúngicas, julgada a estrutura biológica desses parasitos (Mercês et al., 2013; Pimentel et al., 2013; Nishio et al., 2016; Pinheiro et al., 2018).

No entanto, o real mecanismo de ação para os méis desenvolverem a atividade antimicrobiana, não está completamente elucidado. Propõe-se que haja uma relação entre a sua alta osmolaridade, viscosidade, acidez, baixa atividade de água, conteúdo proteico, alto teor de açúcares redutores e o elevado conteúdo de inibidores (Cabral, 2014). Refere-se ainda a vasta variedade de enzimas que são encontradas nos méis, dentre elas, peroxidase, catalase, inulase, diástase, fosfatase ácida, amilase, lipase e $\alpha$-glicosidase, podendo estas estar relacionadas à atividade antimicrobiana (Gonçalves; Alves Filho; Menezes, 2005). 
Em análises microbiológicas, identificam-se inúmeras espécies de Bacillus, cujas existências se justificam uma vez que possuem uma relação harmônica com as abelhas. Exercem uma forte função contra agentes patogênicos e auxiliam para a conservação do produto. As principais espécies descritas são B. cereus, B. licheniformis e B. subtilis. (Pinheiro et al., 2018). A presença dessas bactérias leva a outras hipóteses de como os méis podem exercer a sua farmacodinâmica contra afecções provocadas por agentes etiológicos. Como exemplo cita-se que possa existir a capacidade de síntese de substâncias antimicrobianas contra as bactérias patogênicas, a competição por nutrientes e sítios necessários e à modificação do $\mathrm{pH}, \mathrm{o}$ que inibe o crescimento dos microrganismos que comumente causam perturbações (Cabral, 2014).

Figura 1 - Prováveis mecanismos de ação propostos para o mel:

\section{PROVÁVEIS MECANISMOS DE AÇÃO DOS MÉIS}

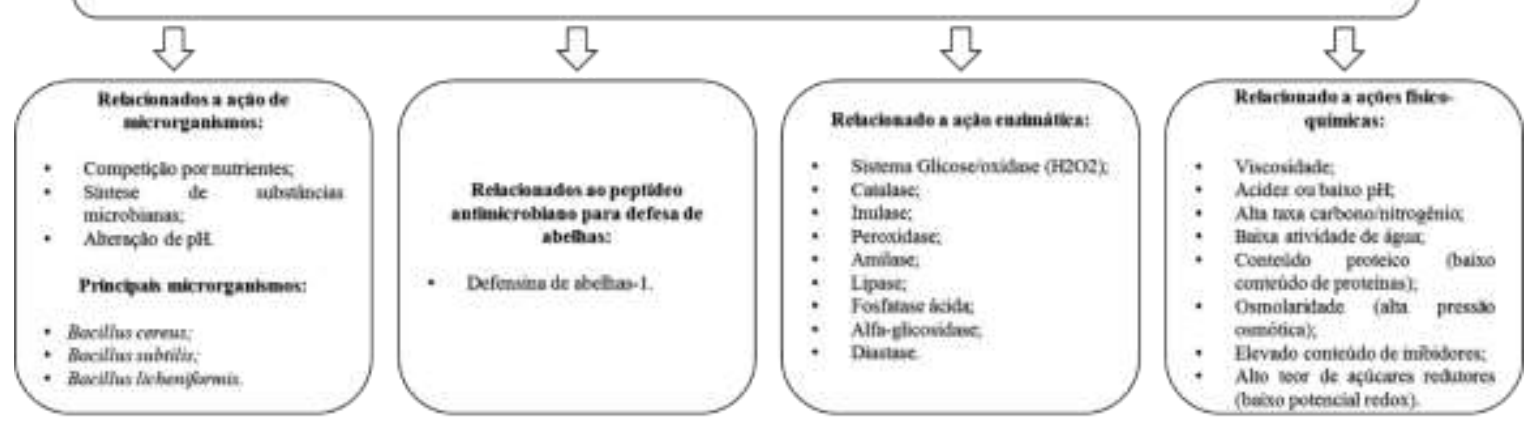

Fonte: Adaptado de Gonçalves; Alves Filho; Menezes (2005); Borsato et al. (2013); Cabral (2014); Pinheiro et al. (2018).

Na pesquisa de Cruz et al. (2014), os experimentos basearam-se na comparação da atividade antimicrobiana de méis de dois sem ferrão, sendo Melipona compressipes e Melipona seminigra, com o mel de Apis mellifera, contra inúmeros microrganismos patogênicos. Todas as variedades de mel testadas apresentaram atividade antimicrobiana. Mais, embora o mel de A. mellifera tenha apresentado maior capacidade inibitória contra o crescimento de Escherichia coli e Chromobacterium violaceum. O mel de M. compressipes teve uma maior capacidade inibitória contra Staphylococcus aureus e Candida albicans, microrganismos mais comuns em casos de infecções oportunistas. E o mel de M. seminigra foi o mais eficiente apenas contra a cepa de Enterococcus faecalis, organismo que mais comumente causam infecções em humanos.

Outro estudo que compara as propriedades antimicrobianas de méis é o de Zulkhairi Amin et al. (2018), avaliando propriedades terapêuticas do mel de abelha sem ferrão (Trigona spp.), com o mel de abelha europeu (Apis spp.). Esse estudo demostrou um papel significativo dos méis de abelha sem ferrão como agente terapêutico em vários problemas de saúde. Sendo mais eficazes que o mel de abelha europeu, e em alguns casos exibindo muitas propriedades terapêuticas exclusivas. Embora a pesquisa não esteja direcionada para abelhas sem ferrão do gênero Melipona, indicou informações cruciais, como, devido à estrutura do ninho, a atividade antimicrobiana dos méis de abelhas nativas, tende a ser mais potente, que os méis de abelha europeu.

No estudo de Jalil, Kasmuri e Hadi (2017), verifica-se a utilização de méis de abelhas sem ferrão no processo de cicatrização de feridas, levando em consideração as propriedades antioxidantes, antimicrobianas, anti-inflamatórias e hidratantes desse produto natural. Obtendo que as propriedades antimicrobianas do mel podem superar a contaminação microbiana e, assim, melhorar a taxa de cura, uma vez que a presença de microrganismos pode atrasar o processo de cicatrização. Levando em consideração as outras propriedades, principalmente a antioxidante, o mel é eficaz na resolução do 
problema, mas é imprescindível entender o mecanismo farmacológico do mel em relação à fisiologia da pele afetada para melhorar a taxa de cicatrização no futuro.

Brown et al. (2020), avaliou as características físicas e antimicrobianas de cinco amostra de mel, sendo duas de Apis mellifera de Trinidad, duas de Frieseomelitta nigra, uma de Trinidad e outro de Tobago e uma amostra fresca de Melipona favosa de Tobago, essa última, espécie de interesse. As propriedades físicas como aparência, $\mathrm{pH}$, teor de umidade, teor de açúcar e densidade específica foram determinados. E a atividade antimicrobiana foi avaliada, embora as concentrações inibitórias mínimas (2 a 16\%) e as concentrações bactericidas mínimas (2 a 32\%) de mel de abelha sem ferrão tenham sido menores do que a de abelhas com ferrão, esses exibiram um amplo espectro de atividade antimicrobiana contra organismos Gram-positivos e Gram-negativos, apresentando níveis de fenol superior ou equivalente aos méis de A. mellifera. Sendo que o mel de M. favosa apresentou a maior atividade antimicrobiana.

Outro estudo que demostra a eficácia dos méis de meliponíneos contra microrganismos é o de Domingos et al. (2020), que avaliou o potencial antibacteriano in vitro do mel de Melipona spp. da região amazônica. Amostras de méis das espécies: Melipona eburnea, Melipona grandis, Melipona flavolineata e Melipona seminigra, foram utilizadas. E os resultados com ensaio de difusão em ágar, demostrou atividade antibacteriana dos quatro méis contra as cepas testadas. Sendo o mel de Melipona flavolineata, o mais eficaz e promissor.

Fernesi et al. (2009), diferentemente dos outros pesquisadores, avaliou efeitos da própolis de abelha sem ferrão e abelha melifera em quatro espécies de bactérias. Os estudos com própolis e geoprópolis são importantes, tendo em vista a migração de componentes ativos desses produtos para o mel, aumentando ainda mais o escopo de substâncias químicas bioativas com efeitos farmacológico ou toxicológico. As amostras utilizadas foram de própolis de Apis mellifera; Scaptotrigona sp. e Melipona quadrifasciata. Sendo que a própolis da última espécie, foi a que melhor se destacou contra Pseudomonas aeruginosa.

Os estudos de Ávila et al. (2019), avaliaram os compostos bioativos e propriedades biológica dos méis de abelha sem ferrão. Os teores de compostos bioativos, análises físico-químicas, antioxidantes e antimicrobianas foram investigadas. Os experimentos realizados se deram pela utilização de trinta e duas amostras de méis do Estado do Paraná (Brasil), com a variabilidade de quatro espécies (vinte e quatro amostras do gênero Melipona e oito do gênero Scaptotrigona). Diferenças consideráveis foram encontradas nos distintos méis de abelhas sem ferrão: propriedades biológicas, físicas, parâmetros químicos e palinológicos. Esse estudo demostrou uma forte relação entre a origem botânica do pólen e as propriedades físicas e biológicas dos méis, além de ressaltar que a atividade antimicrobiana dos méis de abelha sem ferrão avaliada, apresentou valores tão elevados quanto os de mel de Apis mellifera.

Os estudos citados anteriormente retratam confirmações cientificas de experimentos realizados onde os méis de abelha sem ferrão apresenta atividade contra microrganismos. Porém, certamente as pesquisas realizadas até o momento atual, não consentem o entendimento completo ou real sobre a participação de cada um dos fatores físico-químicos, enzimáticos e biológicos (microrganismos e defensinas) sobre a atividade antimicrobiana dos méis. O que se apresenta em literatura sobre esses fatores, é que essas distintas particularidades, atuam em sinergismo, proporcionando a esses alimentos propriedades antimicrobianas únicas, porém variante, que dependera não somente da natureza do produto, como também do processamento e armazenamento (manipulação) (Gonçalves; Alves Filho; Menezes, 2005; Venturini; Sarcinelli; Silva, 2007; Borsato et al., 2013).

A variabilidade de atividade antimicrobiana dependente de cada tipo de mel e as condições que são pertencentes à aptidão antimicrobiana de cada composto ainda permanecem uma incógnita, sendo empecilhos para a aplicação do mel na medicina e, devido a isso, diversos trabalhos são realizados para examinar experimentalmente o comportamento dos microrganismos frente aos diferentes tipos de méis, levando em conta não apenas as espécies de abelhas nativas como também 
a origem alimentar e seus constituintes (Kwakman; Zaat, 2012; Borsato et al., 2013; Cabral, 2014; Cruz, et al. 2014; Rao; Krishnana; Sallehb; Gan, 2016).

\subsection{Perfil tóxico de méis}

A composição dos méis é permeada de variantes, atribuindo potencial e eficácia terapêutica distintas em diferentes espécies. Além dos fatores já relacionados nesse trabalho que podem influenciar diretamente no perfil farmacognóstico do mel, cita-se, ainda, que o processamento, manipulação e estocagem desse produto podem modificar a sua natureza. Compreende-se também que atividades antropogênicas afetam a composição química de fontes limpas, tornando contaminados os recursos, incluindo diversidade botânica (pólen e néctar), edáfica (solo) e climática (água e ar), podendo esse derivado apresentar algum grau de toxidade. (Fernandes; Rosa; Conti-Silva, 2018).

Em referência ao anterior, cita-se o estudo de Bonsucesso et al. (2018), onde foi pesquisado a presença de substâncias tóxicas, como metais na geoprópolis da colméia de Melipona scutellaris, observando que as amostras exibem um padrão metálico semelhante aos dos solos ao redor da colmeia, fontes de contaminação externas que tornam o material produzido pelas abelhas, tóxicos. Podendo até mesmo outros metabolitos, como o mel, torna-se tóxico, visto que, como os constituintes fitoquímicos presentes na própolis, os metais contidos na geoprópolis podem ser difundidos no mel durante o período em que este fica armazenado nos potes de cerume, conferindo-o propriedades toxicológicas, pois alteram a composição química e consequentemente a atividade biológica (Batiston, 2017).

Agora, cita-se que esse tipo de mel é sazonalmente coletado nos locais onde as colônias dessas abelhas são identificadas em seu meio natural, por ação de meleiros. Esse produto, não passa pelas devidas medidas de controle de qualidade, mínimas estabelecidas pelas Boas Práticas de Fabricação, associados principalmente a umidade elevada (21\% a $45 \%$ ). Isso é, sabe-se que os méis de abelhas sem ferrão apresentam característica higroscopia, assim consequentemente elevada atividade de água, o que o torna susceptível ao crescimento microbiano, principalmente ao relato de relações harmônicas entre as abelhas e microrganismos (bacilos e leveduras - que fazem parte da composição original dos méis) (Camargo; Oliveira; Berto, 2017).

Para mais, em relação ao potencial tóxico, tem-se a precisão de que os equipamentos utilizados para a coleta e o manejo do mel são considerados as principais fontes de contaminação por microrganismos patogênicos, aumentando consideravelmente o perfil microbiológico. Assim verifica-se que os métodos de manejo, colheita e beneficiamento são falhos, o que desagrega valor ao produto, dificulta sua comercialização oficial, reduz significativamente seu tempo de prateleira e torna o produto um potencial risco ao consumidor (Pinheiro et al., 2018).

A exemplo de microrganismo comumente encontrados como contaminantes em méis elucida-se pesquisas como as de Kwakman e Zaat (2012), onde citam que o mel cru de Apis mellifera pode apresentar esporos bacterianos, especialmente os de Bacillus spp., e esporos patogênicos de Clostridium botulinum. Pinheiro et al. (2018), realiza estudos com méis Melipona subnitida, da região semiárida do Brasil, onde pôde identificar amostras com espécies de Bacillus, Staphylococcus spp., C. botulinum tipo C e C. perfringens, além de uma rica microbiota em fungos.

Fernandes, Rosa e Conti-Silva (2018), concretizam pesquisas sobre características microbiológicas dos méis de abelha Melipona fasciculata, evidenciando que uma das amostras analisadas apresentaram leveduras a um nível de 105 UFC.g. 1, estando acima do máximo recomendado pela legislação brasileira (100 UFC.g. ${ }^{-1}$ ) em comparação com a da Apis, tomando-a inapropriada para consumo. Felix (2019), cita a existência de microrganismos, que se encontram naturalmente em toda área de extração do mel e no corpo das abelhas. Estes podem levar a contaminação do mel, que é caracterizada por fermentação do produto. 
Em contrapartida, os méis produzidos por meliponários certificados, realizam o máximo de cuidados para elevar a qualidade do produto, diminuindo seu risco de toxidade. Os métodos utilizados, embora empíricos, auxiliam na conservação e qualidade do produto. Podendo citar 4 principais técnicas: fermentação, desidratação, refrigeração e pasteurização (Camargo; Oliveira; Berto, 2017). Ainda se elenca outro processo mais moderno, utilizados nos méis de Manuka e Revamil (méis de grau médico, derivado de Apis mellifera), esses produtos devem ser esterilizados para extinguir potenciais microrganismos ou esporos bacterianos. E essa esterilização se dar por processo de irradiação gama, artifício mais indicado para eliminação de potenciais ricos microbiológicos, porem de alto custo, motivo pelo qual é empregado principalmente no mercado internacional (Kwakman; Zaat, 2012).

Embora a principal causa para ocasionar toxidade aos méis, seja referenciada em literatura pela contaminação microbiológica, ainda existe outros aspectos a se considerar, onde o perfil toxicológico se alberga no produto (Pinheiro et al., 2018; Fernandes; Rosa; Conti-Silva, 2018). Como, considerando a etologia de determinadas espécies de abelhas nativas, operárias do gênero Lestrimelitta, abelhas eussociais que podem parasitar ninhos de outras abelhas. Esse gênero foi elucidado por Nogueira-Neto em 1997, e embora alguns estudos tenham se realizados sobre esses insetos, há um escopo limitado de informações disponíveis (Alves et al., 2011).

Os insetos citados anteriormente não apresentam corbícula ou cesta de pólen, devido a isso não desenvolve o comportamento de coletar e transportar essa partícula. Assim essas abelhas são consideradas pilhadoras ou cleptobióticas, onde surrupiar ninhos de outras espécies de abelhas, vivendo à custa dos metabolitos armazenadas na colmeia. Em destaque, a espécie Lestrimelitta limao, ou abelha limão, recebe essa denominação por exalar forte odor característico da fruta. Essa espécie saqueia outras colmeias através da liberação de substâncias voláteis produzidas por suas glândulas mandibulares, os chamados terpenoides, esses elementos contaminam os metabolitos da colmeia, tornando-os perigoso se consumidos pelo homem, pois são considerados tóxicos, principalmente o mel, que geralmente se encontra abundante no ninho. Outra espécie também é de notoriedade, Lestrimelitta rufipes, além dos gêneros Cleptotrigona e Trichotrigona, porém os estudos evolutivos demostram comportamentos diferentes ao habito de saquear, variante de abelha para abelha (Alves et al., 2011).

Retrata ainda há necessidade de legislações específicas e estudos de farmacologia e toxicologia direcionados aos méis de abelha sem ferrão, uma vez que as vendas dos méis ocorrem na maioria das vezes, em circuitos curtos de comercialização, ou seja, vendas diretas em propriedade particulares ou em feiras livres (Teixeira, 2007).

Devido as peculiaridades na composição físico-química, as normas e valores de referência preconizados para o controle da qualidade e comercialização de mel, nas legislações nacionais (Brasil, 2000) e internacionais (FAO, 2001), não são aplicadas aos derivados das abelhas nativas. Assim, a inexistência de legislações exclusivas aos metabolitos de abelha sem ferrão, impede a formação da identidade e de um padrão próprio para os produtos (Camargo; Oliveira; Berto, 2017). O que dificulta a ação de órgãos fiscalizadores por não apresentarem dados referenciados para inspeção. Isso aumenta o risco ao consumidor, pois não há uma garantia da qualidade, segurança e eficácia dos méis.

Ainda fazendo referência a manipulação dos méis, cita as alterações físico-químicas associadas a adulteração. As principais formas de adulterações encontradas em literaturas são: adição de açúcares, principalmente os comerciais e superaquecimento. Essas alterações modificam parâmetros de pureza dos méis, não só diminuem a qualidade, como pode gerar algum potencial tóxico, dependendo da quantidade adicionada (alérgenos), a temperatura exposta (alterações ao nível de atividade de água (Aa) e pH, degradação de fitoquímicos e inativação enzimáticas, características que definem as condições para o crescimento microbiano no produto) e da susceptibilidade do indivíduo (patologias) (Gonçalves; Alves Filho; Menezes, 2005; Camargo; Oliveira; Berto, 2017; Felix, 2019).

Sendo assim, a disseminação de informações sobre ecologia, comportamento e bionomia das espécies de abelhas nativas, a elaboração de legislações próprias, o melhoramento de técnicas para controle microbiológico, os estudos de controle 
de qualidade e aspectos físico- químicos para se identificar adulterações, e a avaliação toxicológica, é significativamente relevante, para traçar um perfil toxicológico e para garantir a qualidade, segurança e eficácia desse produto que tem ampla empregabilidade (Bárbara et al., 2015).

Figura 2 - Casualidades que referenciam a toxidade dos méis.

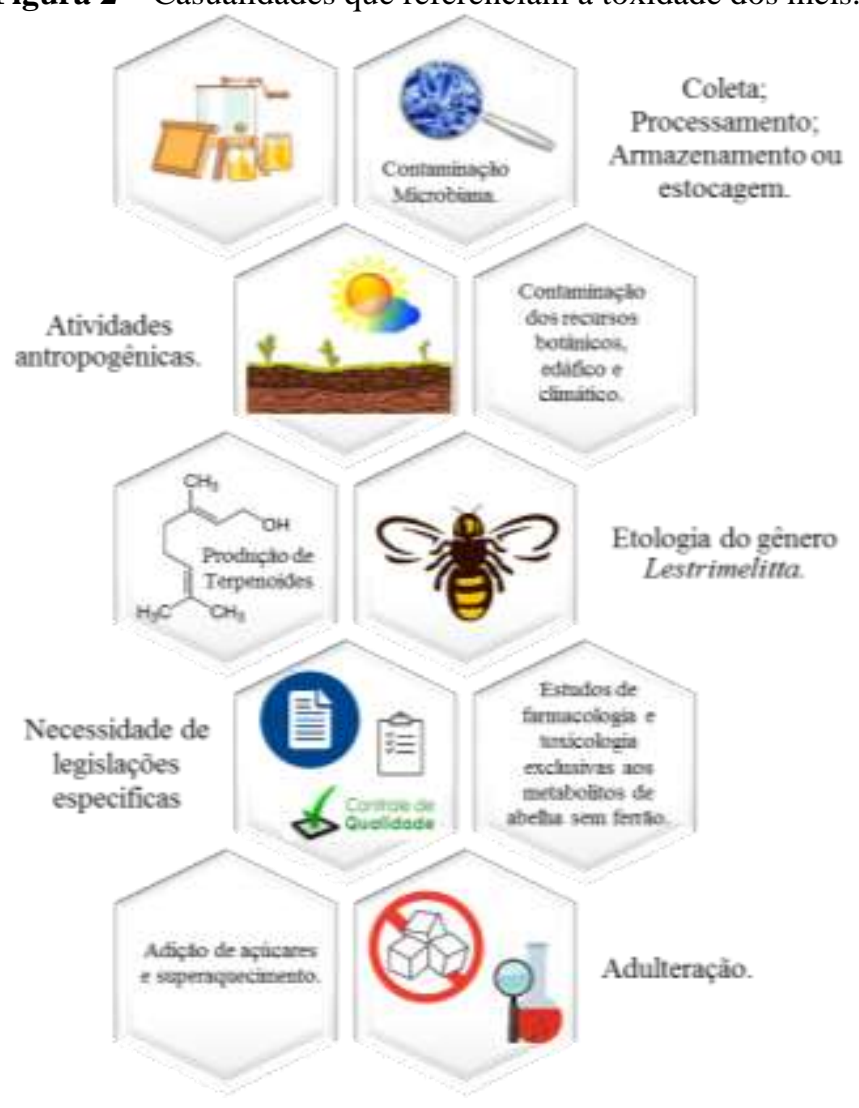

Fonte: Autores (2021).

\section{Considerações Finais}

Por meio da abordagem que esta revisão integrativa possibilitou, verificou-se a diversidade de abelhas do gênero Melipona produtoras de mel. Em relação à composição dos méis foi evidenciado uma variedade de constituintes químicos e biológicos. E mediante a leitura dos artigos foi possível descrever o potencial antimicrobiano dos méis de abelhas nativas, sendo este, variável. Porém, os méis de meliponíneos podem ser considerados candidatos promissores para pesquisa e desenvolvimento de novos antimicrobianos voltados para o tratamento de infecções agudas ou crônicas. Além de caracterizar o perfil de toxicidade dos méis, destacando-se a contaminação microbiológica como a principal causa de toxicidade. Os resultados desta revisão contribuíram para a construção do conhecimento acerca do tema abordado, além de servir como base para o desenvolvimento de novas pesquisas.

\section{Referências}

Alves, L. H. S., et al. (2011). Nota sobre abelhas Lestrimelitta rufipes (Freise) (Hymenoptera, Meliponina), atraídas por armadilhas com iscas odoríferas, na região Sul Fluminense do Estado do Rio de Janeiro. Biota Neotrop., 11, 1. 10.1590/S1676-06032011000100040.

Ávila, S., Hornung, P. S., Teixeira, G. L., Malunga, L. N., Apea-Bah, F. B., Beux, M. R., \& Ribani, R. H. (2019). Compostos bioativos e propriedades biológicas do mel de abelhas sem ferrão do Brasil possuem forte relação com a origem floral do pólen. Food Research International. 10.1016 / j.foodres.2019.01.068 
Brasil. Conselho Nacional Do Meio Ambiente. Resolução no 346, de 16 de agosto de 2004. Publicada no DOU no 158, de 17 de agosto de 2004, Seção 1, página 70.

Brasil. Agência Nacional De Vigilância Sanitária. Resolução n 14, de 28 de março de 2014. Republicada no DOU de 21 de agosto de 2006, e suas atualizações, incisos III, do art. $2^{\circ}$, III e IV, do art. $7^{\circ}$ da Lei n. ${ }^{\circ} 9.782$, de 1999.

Brasil. Ministério da Agricultura Pecuária e Abastecimento. Instrução Normativa n ${ }^{\circ} 11$, de 20 de outubro de 2000, Regulamento técnico de identidade e qualidade do mel. Diário Oficial da República Federativa do Brasil, Brasília, DF, 20 out 2000. Seção 1, p. 19696-19697.

Barcelos, A. do N., \& Harter-Marques, B. (2019). Recursos alimentares de Melipona quadrifasciata quadrifasciata (Hymenoptera: Meliponinae) na restinga do sul de santa Catarina, Brasil - Capítulo 1. Coletânea Nacional sobre Entomologia, Atena Editora. 10.22533/at.ed.5041909071.

Bárbara, M. S., Machado, C. S., Sodré, G. S., Dias, L. G., Estevinho, L. M., \& Carvalho, C. A. L. (2015). Microbiological Assessment, Nutritional Characterization and Phenolic Compounds of Bee Pollen from Mellipona mandacaia Smith, 1983. Molecules, 20, $12525-12544$. $10.3390 /$ molecules 200712525 .

Batiston, T. F. T. P. (2017). Atividade antimicrobiana de diferentes méis de abelha sem ferrão. Dissertação de mestrado, Universidade do Estado de Santa Catarina (UDESC), Chapecó, SC, Brasil.

Borsato, D. M., Esmerino, L. A., Farago, P. V., Miguel, M. D. \& Miguel, O. G (2013). Atividade antimicrobiana de méis produzidos por meliponíneos nativos do Paraná (Brasil). Boletim do Centro de Pesquisa de Processamento de Alimentos, 31(1), 57-66. http://dx.doi.org/10.5380/cep.v31i1.32700.

Bonamigo, T., Campos, J. F, Alfredo, T. M, Balestieri, J. B. P., Cardoso, C. A. L., Paredes-Gamero, E. J., \& Santos, E. L (2017). Atividades antioxidantes, citotóxicas e tóxicas da própolis de duas abelhas nativas no Brasil: Scaptotrigona depilis e Melipona quadrifasciata anthidioides. Oxidative Medicine and Cellular Longevity, 1-12. 10.1155 / 2017/1038153

Bonsucesso, J. S., Gloaguen, T. V., do Nascimento, A. S., de Carvalho, C. A. L., \& Dias, F. (2018). Metais em geoprópolis da colméia de Melipona scutellaris em ambientes urbanos. Science of The Total Environment, 634, 687-694. 10.1016 /j.scitotenv.2018.04.022.

Brown, E., O'Brien, M., Georges, K., \& Suepaul, S. (2020). Características físicas e propriedades antimicrobianas de mel de abelha de Apis mellifera, Frieseomelitta nigra e Melipona favosa de apiários em Trinidad e Tobago. BMC Complementary Medicine and Therapies, 20 (1). 10.1186 / s12906-020-28295 .

Cabral, V. A. (2014). Atividade antimicrobiana do mel e geoprópolis de abelha uruçu (Melipona scutellaris Latreille, 1811). Monografia (Bacharel em Ciências Biológicas), Universidade Federal da Paraíba (UFPB), João Pessoa, PE, Brasil.

Campêlo, M. C., Freire, D. A. C., Abrantes, M. R., de Sousa, Ê. S., \& da Silva, J. B. A. (2015). Potencial antimicrobiano de própolis e cera de diferentes espécies de abelhas sem ferrão. Acta Veterinaria Brasilica, 9(4), 397-400. 10.21708/avb.2015.9.4.5406.

Camargo, R. C. R. de, Oliveira, K. L. de, \& Berto, M. I. (2017). Mel de abelhas sem ferrão: proposta de regulamentação. Brazilian Journal of Food Technology, 20(0). 10.1590/1981-6723.15716.

Costa Neto, E. M., \& Resende, J. J. (2004). A percepção de animais como "insetos" e sua utilização como recursos medicinais na cidade de Feira de Santana, Estado da Bahia, Brasil. Acta Scientiarum. Biological Sciences, 26(2). 10.4025/actascibiolsci.v26i2.1612.

Costa Neto, E. M., \& Pacheco, J. M. (2005). Utilização medicinal de insetos no povoado de Pedra Branca, Santa Terezinha, Bahia, Brasil. Biotemas, 18(1), 113-133. 10.5007/\%25x.

Cruz, C. B. N. da, Pieri, F. A., Carvalho-Zilse, G. A., Orlandi, P. P., Nunes-Silva, C. G., \& Leomil, L. (2014). Atividade antimicrobiana de méis de duas espécies de abelhas sem ferrão e Apis mellifera (Hymenoptera: Apidae) contra microrganismos patogênicos. Acta Amazonica, 44 (2), 287-290. 10.1590 / s0044-59672014000200015.

Dorigo, A. S., Rosa-Fontana, A. de S., Soares-Lima, H. M., Galaschi-Teixeira, J. S., Nocelli, R. C. F., \& Malaspina, O. (2019). Protocolo de criação in vitro de larvas para a espécie de abelha sem ferrão Melipona scutellaris para estudos toxicológicos. Plos One, 14 (3), e0213109. 10.1371 / journal.pone.0213109.

Domingos, S. C. B. (2019). Atividade antibacteriana dos méis de abelhas-sem-ferrão do gênero Melipona da Amazônia (Apidae: Meliponina). Dissertação de Pós-graduação, Universidade Federal Do Acre (UFAC), Rio Branco, AC, Brasil.

Domingos, S. C. B., Clebis, V. H., Nakazato, G., Oliveira, A. G., Takayama Kobayashi, R. K., Peruquetti, R. C., \& Medeiros, L. dos S. (2020). Atividade antibacteriana de méis de abelhas amazônicas sem ferrão de Melipona spp. e seus efeitos na morfologia das células bacterianas. Jornal da Ciência da Alimentação e Agricultura. 10.1002 / jsfa.10828.

Dutra, R. P., Nogueira, A. M. C., Marques, R. R. O., Costa, M. C. P., \& Ribeiro, M. N. S. (2018). Avaliação farmacognóstica de geoprópolis de Melipona fasciculata Smith da Baixada maranhense, Brasil. Revista Brasileira de Farmacognosia, 18(4), 557-562. http://dx.doi.org/10.1590/S0102$695 \times 2008000400010$.

Felix, M. D. G (2019). Análises físico-químicas para determinação da qualidade de méis da Paraíba - PB. Trabalho de Conclusão de Curso, Universidade Federal da Paraíba (UFPB), Areia, PB, Brasil.

Fernandes, R. T., Rosa, I. G., \& Silva, A. C. C. (2018). Microbiological and physical-chemical characteristics of honeys from the bee Melipona fasciculata produced in two regions of Brazil. Ciência Rural, 48(5), e20180025. https://doi.org/10.1590/0103-8478cr20180025.

Food And Agriculture Organization Of The United Nations - FAO. Codex Alimentarius Commission. Codex Stan 12-1981: Codex Standard for honey. Roma: FAO, 2001. 8 p. 
Gonçalves, A. L., Alves Filho, A., \& Menezes, H. (2005). Atividade antimicrobiana do mel da abelha nativa sem ferrão Nannotrigona testaceicornis (Hymenoptera: Apidae, Meliponini). Arquivos do Instituto Biológico, São Paulo, 72(4), 455-459. http://www.biologico.agricultura.sp.gov.br/ uploads/docs/arq/v72_4/goncalves.PDF.

Grzegozeski, T. L. (2015). Influência da espécie de abelha e da origem floral do mel sobre a atividade antimicrobiana frente às bactérias Staphylococcus aureus e Escherichia coli. Trabalho de Conclusão de Curso, Universidade Tecnológica Federal do Paraná (UTFPR), Campo Mourão, PA, Brasil.

Holanda, C. A., Oliveira, A. R., Costa, M. C. P., Ribeiro, M. N. de S., Souza, J. L. \& Araújo, M. J. A. M. (2012). Qualidade dos méis produzidos por Melipona fasciculata Smith da região do cerrado maranhense. Quim. Nova, 35(1), 55-58. https://www.scielo.br/pdf/qn/v35n1/v35n1a11.PDF.

Jamil Neto, T. (2006). Estudos morfométricos sobre espécies de abelhas da tribo Meliponini (Hymenoptera: Apidae). Tese de Doutorado, Universidade Federal do Amazonas (UFAM), Manaus, AM, Brasil.

Jalil, M. A. A., Kasmuri, A. R., \& Hadi, H. (2017). Stingless Bee Honey, the Natural Wound. Healer: a review, 30 (2), 66-75. 10.1159/000458416.

Kwakman, P. H. S., \& Zaat, S. A. J. (2011). Critical Review Antibacterial Components of Honey. IUBMB Life, 64 (1), 48-55. 10.1002 / iub.578.

Lima, A. P. (2004). Aspectos da biologia de Melipona rufiventris Lepeletier, 1836 e Melipona mondury Smith, 1863 (Hymenoptera: Apidae, Meliponina). Dissertação de mestrado, Universidade Federal de Viçosa (UFV), Minas Gerais, MG, Brasil.

Lima, F. V. de O., \& Silvestre, R. (2017). Abelhas (Hymenoptera, Apidae sensu lato) do Estado de Mato Grosso do Sul, Brasil. Iheringia, Série Zoologia, 107. $10.1590 / 1678-4766 \mathrm{e} 2017123$.

Martins, A. C. L., Rêgo, M. M. C., Carreira, L. M. M., \& Albuquerque, P. M. C. (2011). Espectro polínico de mel de tiúba (Melipona fasciculata Smith, 1854, Hymenoptera, Apidae). Acta Amazonica, 41(2), 183-190. 10.1590/S0044-59672011000200001.

Mercês, M. D., Peralta, E. D., Uetanabaro, A. P. T. \& Lucchese, A. M. (2013). Atividade antimicrobiana de méis de cinco espécies de abelhas brasileiras sem ferrão. Ciência Rural, Santa Maria, 43(4), 672-675. 10.1590/S0103-84782013005000016.

Michener, C. D. (2000). The bees of the world. The Johns Hopkins University Press, Baltimore, Maryland. 913 pp.

Nishio, E. K., et al. (2016). Antibacterial synergic effect of honey from two stingless bees: Scaptotrigona bipunctata Lepeletier, 1836, and S. postica Latreille, 1807. Scientific Reports, 6, 1-8. 10.1038 / srep21641 (2016).

Obiols, C. L. Y. (2008). Gênero Melipona Illiger, 1806 em Minas Gerais — Identificação, Distribuição e Estado Atual de Conservação. Dissertação de Pósgraduação, Universidade Federal de Minas Gerais (UFMG), Belo Horizonte, MG, Brasil.

Oliveira. F. F. de , Richers, B. T. T., Silva, J. R. da , Farias, R. C., \& Matos, T. A. de L. (2013).Guia Ilustrado das Abelhas "Sem-Ferrão"das Reservas Amanã e Mamirauá, Amazonas, Brasil (Hymenoptera, Apidae, Meliponini). 267 f. MCT/IDSM: Copyright. https://www.mamiraua.org.br/documentos/203b72258e1fc57b8b8255d87795daa1.PDF.

Pereira, F. de M., Souza, B. de A., \& Lopes, M. T. do R. (2017). Criação de abelhas-sem-ferrão. 31 p. Teresina: Embrapa Meio-Norte. https://www.infoteca.cnptia.embrapa.br/infoteca/bitstream/doc/1079116/1/CriacaoAbelhaSemFerrao.PDF.

Pimentel, R. B. de Q., da Costa, C. A., Albuquerque, P. M., \& Junior, S. D. (2013). Antimicrobial activity and rutin identification of honey produced by the stingless bee Melipona compressipes manaosensis and commercial honey. BMC Complementary and Alternative Medicine, 13 (1). 10.1186 / 1472-6882-13151.

Pinheiro, C. G. M. E., Abrantes, M. R., Silva, R. O. S., Oliveira Junior, C. A., Lobato, F. C. F., \& Silva, J. B. A (2018). Microbiological quality of honey from stingless bee, jandaíra (Melipona subnitida), from the semiarid region of Brazil. Ciência Rural, 48(9), e20180151. https://doi.org/10.1590/0103$8478 \mathrm{cr} 20180151$.

Raoa, P. V., Krishnana, K. T., \& Gan, N. S. (2016). Biological and therapeutic effects of honey produced by honey bees and stingless bees: a comparative review. Revista Brasileira de Farmacognosia, 26, 657-664. https://doi.org/10.1016/j.bjp.2016.01.012.

Rodrigues, A. E., Silva, E. M. S. da, Beserra, E. M. F., \& Rodrigues, M. L. (2005). Análise físico-química dos méis das abelhas Apis mellifera e Melipona scutellaris produzidos em regiões distintas no Estado da Paraíba. Ciência Rural, 35(5), 1166-1171. 10.1590/s0103-84782005000500028.

Rodrigues, A. dos S. (2005). Etnoconhecimento sobre abelhas sem ferrão: saberes e práticas dos índios Guarani M'BYÁ na mata atlântica. Monografia de Mestrado, Escola Superior de Agricultura "Luiz de Queiroz", São Paulo, SP, Brasil.

Romeiro, E. T., Oliveira, I. D., Carvalho, E. F. (2015). Insetos como alternativa alimentar: artigo de revisão. Revista de Comportamento, Cultura e Sociedade, 4(1). http://www3.sp.senac.br/hotsites/blogs/revistacontextos/wpcontent/uploads/2015/10/5 4_CA_artigo_ed_Vol_4_n_1_15_2.PDF.

Sanches, M. A. (2012). A própolis de abelhas sem ferrão e suas propriedades terapêuticas. Apta regional, 9(1). http://www.aptaregional.sp.gov.br/acesse-osartigos-pesquisa-e-tecnologia/edicao-2012/janeiro-junho-2/1180-a-propolis-de-abelhas-sem-ferrao-e-suas-propriedades-

terapeuticas/file.html\#: :text=V\%C3\%A1rias\%20atividades\%20terap\%C3\%AAuticas\%20foram\%20detectadas,de\%20morte\%20ce

lular\%2C\%20entre\%20outras.PDF.

Silva, W. P., \& Paz, J. R. L. (2012). Abelhas sem ferrão: muito mais do que uma importância econômica. Natureza on line, 10(3), 146-152. https://www.researchgate.net/ profile/Joicelene_Paz/publication/282861548_Abelhas_sem_ferrao_muito_mais_do_que_uma_importancia_economica/link s/561 fe47 08aea35f267e10fa/Abelhas-sem-ferrao-muito-mais-do-que-uma-importancia-economica.PDF.

Silva, J. B., Costa, K. M. F. M., Coelho, W. A. C., Paiva, K. A. R., Costa, G. A. V., Salatino, A., Freitas, C. I. A., \& Batista, J. S. (2016). Quantificação de fenóis, flavonoides totais e atividades farmacológicas de geoprópolis de Plebeia aff. Flavocincta do Rio Grande do Norte. Pesq. Vet. Bras., 36(9), 874-880. http://dx.doi.org/10.1590/s0100-736x2016000900014. 
Research, Society and Development, v. 10, n. 4, e13510413903, 2021

(CC BY 4.0) | ISSN 2525-3409 | DOI: http://dx.doi.org/10.33448/rsd-v10i4.13903

Silva, L. M. C. da. (2016). Atividade antibacteriana de méis de meliponíneos obtidos de diferentes regiões do estado do Paraná (Brasil). Trabalho de Conclusão de Curso, Universidade Tecnológica Federal do Paraná (UTFP), Campo Mourão, PA, Brasil.

Silveira, F. A., Melo, G. A. R., \& Almeida, E. A. B. (2002). Abelhas brasileiras: Sistemática e Identificaçã.

Simonetti, P. A. C. (2019). Sistema de Avaliação do Potencial para Inovação de Biomoléculas - SInBIOMOL:da biodiversidade Amazônica a fármacos. Dissertação de mestrado, Universidade Federal do Amazonas (UFAM), Manaus, AM, Brasil.

Sousa, J. M. B., Aquino, I. D. S., Magnani, M., Albuquerque, J. R. de, Santos, G. G. dos, \& Souza, E. L. de. (2013). Aspectos físico-químicos e perfil sensorial de méis de abelhas sem ferrão da região do Seridó, Estado do Rio Grande do Norte, Brasil. Semina: Ciências Agrárias, 34(4). 10.5433/1679$0359.2013 v 34 \mathrm{n} 4 \mathrm{p} 1765$.

Souza, B. de A. (2008). Caracterização físico-química e qualidade microbiológica de amostras de mel de abelhas sem ferrão (Apidae, Meliponina) do estado da Bahia, com ênfase em Melipona Illiger, 1806. Dissertação de Doutorado, Universidade de São Paulo (USP), Piracicaba, SP, Brasil.

Teixeira, A. F. R. (2007). Princípios Agroecológicos Aplicados à Criação de Abelhas nativas sem ferrão. Rev. Bras. de Agroecologia, 2(2). https://biblioteca.incaper.es.gov.br/digital/bitstream/item/81/1/Principios-Agroecologicos-Aplicados-a-Criacao-de-Abelhas.PDF.

Venturieri, G. C., Raiol, V. D. F. O., \& Pereira, C. A. B. (2003). Avaliação da introdução da criação racional de Melipona fasciculata (Apidae: Meliponina), entre os agricultores familiares de Bragança-PA, Brasil. Biota Neotropica, 3(2), 1-7. 10.1590/S1676-06032003000200003.

Venturieri, G. C. (2008). Criação de abelhas indígenas sem ferrão. Belém, PA: Embrapa Amazônia Oriental. https://ainfo.cnptia.embrapa.br/digital/bitstream/item/60448/1/aPICULTURA.PDF.

Venturieri, G. C., Oliveira, P. S., Vasconcelos, M. A. M. de., \& Mattietto, R. de A. (2007). Caracterização, colheita, conservação e embalagem de méis de abelhas indígenas sem ferrão. Ambrapa $\quad$ Amânia https://www.infoteca.cnptia.embrapa.br/infoteca/bitstream/doc/409008/1/LivroMeisASFPDF.

Venturini, K. S., Sarcinelli, M. F., \& Silva, L. C. da. (2007). Características do Mel. Boletim Técnico, Universidade Federal do Espírito Santo - UFES

Zamora, L. G., Beukelman, C. J., van den Berg, A. J. J., Aerts, P. C., Quarles van Ufford, H. C., Nijland, R., \& Arias, M. L. (2017). Uma visão sobre as propriedades antibiofilme do mel de abelha sem ferrão da Costa Rica. Journal of Wound Care, 26 (4), 168-177. 10.12968 / jowc.2017.26.4.168

Zulkhairi Amin, F. A., Sabri, S.., Mohammad, S. M., Ismail, M.., Chan, K. W., Ismail, N., \& Zawawi, N. (2018). Propriedades terapêuticas do mel de abelha sem ferrão em comparação com o mel de abelha europeu. Advances in Pharmacological Sciences, 2018, 1-12. 10.1155 / 2018/6179596. 